\title{
- MITOVI 0 SIBILI I DAFNE U POEZIJI MARINE CVETAJEVE I SILVIJE PLAT
}

\author{
DAJANA MILOVANOV ${ }^{1}$ \\ Univerzitet u Novom Sadu, \\ Filozofski fakultet, \\ Beograd, Srbija
}

U radu se analizira ciklus pesama Sibila Marine Cvetajeve i tzv. ciklus 0 pčelama koji čini pet pesama iz zbirke Arijel Silvije Plat u kontekstu mitova o Dafne i Sibili. Prvim dvema pesmama iz oba ciklusa posvećena je posebna pažnja u cilju rasvetljavanja bliskosti poetičkih traganja američke i ruske pesnikinje. Figure Dafne i Sibile na specifičan način su slivene u jednu lirsku junakinju čiji je proces inicijacije u pesničko stvaranje opisan kroz resemantizovanje mitskog narativa.

Ključne reči: mit, Dafne, Sibila, Silvija Plat, Marina Cvetajeva, inicijacija, poezija.

Pesnikinje neretko rehabilituju manje ili više poznate ženske figure iz kulturne baštine i kroz njih problematizuju ulogu žene i ženskog stvaralaštva. Ozlem Gorej (Özlem Görey) u svojoj doktorskoj tezi Tri Sibile na stativu: revizionarsko mitotvorstvo u poeziji H. D., Silvije Plat i Edrijen Rič (Three Sybils on a Tripod: Revisionary Mythmaking in the Poetry of H. D., Sylvia Plath, and Adrienne Rich) analizira strategije kroz koje ženski pesnički glas progovara kroz mit i pre svega ženske junakinje, resemantizujući njihovu tradicionalnu ulogu u mitskom narativu. U nizu figura poput Medeje, Elektre, Klitemnestre, Meduze, koje su analizirane u kontekstu poezije Silvije Plat (Sylvia Plath), izostaju dve koje ni $\mathrm{u}$ jednoj njenoj pesmi nisu imenovane, ali se na njih nedvosmisleno aludira - Dafne i Sibila koja, premda pomenuta u naslovu, nije prepoznata kao važan podtekst u ciklusu o pčelama koji čini pet pesama iz zbirke Arijel (Ariel): Sastanak pčela (The Bee Meeting), Prispeće košnice (The Arrival of the Bee Box), Ubodi (Stings), Roj (The Swarm) $i$ Zimovanje (Wintering). Sibila kao proročica lišena tela i telesnog i Dafne kao žena-drvo posebno su značajne i u poeziji Marine Cvetajeve (Мари́на Цвета́eва) u kojoj zauzimaju centralno mesto u razvoju predstave o ženi-stvaraocu (Gove 1977), te se poetika ruske i američke pesnikinje pokazuju kao bliske na putu ka rasvetljavanju uloge ženskog tela

1 Kontakt podaci (Email): dacam93@gmail.com 
i njenog poetskog glasa u književnoj tradiciji. Nastojaćemo da pokažemo u kakvom su dijalogu „drvo među devojkama” Marine Cvetajeve i lirska junakinja Silvije Plat, „u drvo pretvorena", i na koji način se poetike ovih dveju pesnikinja međusobno dopunjuju.

Inspirisana Sibilom (Eine Sibylle) Rajnera Marije Rilkea (Reiner Maria Rilke), (vetajeva je 1922/23. godine napisala svoju verziju mita u ciklusu od tri pesme Sibila (Сивилла), od kojih su prve dve prevedene na srpski u okviru izbora Pesme i poeme. Za potrebe naše analize, prve dve pesme su ključne, te će o trećoj biti reči samo u kontekstu celine pesničke vizije ostvarene kroz različite pojavne oblike Sibile. Pesnički opus Silvije Plat je, pak, daleko skromnijeg obima, što zbog kratkog stvaralačkog života, što zbog različitih poetičkih načela, teje Arijel preveden u celosti u okviru izbora Ljiljane Đurđić Rani odlazak - od pet pomenutih pesama koje čine ciklus o pčelama, za našu analizu su posebno važne prve dve, Sastanak pčela i Prispeće košnice. Obe pesnikinje su među svoje pesničke teme uvrstile čitav niz mitoloških i biblijskih junakinja, ali Dafne i Sibila predstavljaju posebno čvorište koje povezuje dve geografski, a naposletku i hronološki udaljene poetske vizije naime, i Marina Cvetajeva i Silvija Plat stvaraju novi, hibridni mit spajanjem elemenata iz dva različita „preobražaja” u Ovidijevim Metamorfozama (P. Ovidius Naso, Metamorphoses) Kod Cvetajeve, Sibili se pripisuju Dafnine osobine, dok je kod Silvije Plat obrnuto - lirska junakinja prisvaja mitološki narativ o ženi pretvorenoj u biljku (drvo), ali je ishodište ovog svojevrsnog upisivanja mita u tekstualno telo u narativu o Sibili. Obema su Metamorfoze poslužile kao osnovna podloga za dalju nadgradnju mita, te se valja u kratkim crtama osvnuti na ključne elemente preobražaja Dafne i Sibile. U prvom, Kupidon je, zbog Apolonovog ismevanja, odapeo dve strele: jednu ljubavnu, u podrugljivog boga, drugu za beg od ljubavi, u nimfu Dafne: „Mnogi su prosili nju, a ona odbija prosce, / Ne zna, ne trpi muškog, po besputnim luzima šeće, / Ne mari, što je Himen, što Amor, ženidba, što je" (Met. 1. 478-480) Kao i Sibila, i ona nastoji da sačuva devičanstvo od nasrtljivog boga kojeg obuzima plamen i to čini molbom: „Oče, pomozi! O zemljo, zini il' ovaj / Oblik što čini, da trpim, prom'jeni, da nema ga više!" (Met. 1. 545-546), i preobražava se u lovoriku čije grane ovenčavaju pesnike, odnosno u nepomično stablo. Plamen i vatra kao destruktivne sile i nepomičnost ženskog tela postaće centralni motivi kod dveju pesnikinja, uz treći, možda i najvažniji, koji preuzimaju iz mita o Sibili: postepeno smanjenje i zatvaranje tela u posudu/teglu zvanu ampulla, što je danas u medicinskoj terminologiji naziv za deo materice. Sibila je, naime, takođe bila objekat Apolonove seksualne želje, ali je pokušala da ga prevari traživši onoliko godina života koliko zrna peska staje u šaku. Nakon što joj je Apolon ispunio želju, ipak je odlučila da sačuva devičanstvo zaboravivši da nije tražila večnu mladost. U trenutku kad je Eneja sreće, ona ima 700 godina i telo koje se od starosti skupilo: „Ja ću se tako prom'jenit, da nitko me videti ne će, / Al' će me znati po glasu, jer ostavit glas će mi sudba" (Ovidije 1991: 367).

Ipak, za pesnikinje ključni element mita izostaje iz Ovidijeve verzije i nalazi se u Satirikonu Petronija Arbitera (Satyricon, Petronii Arbitri), a preuzima ga i T. S. Eliot (T. S. Eliot) u motou Puste zemlje (The Waste Land): „A Sibilu sam vido s rođene oči u Kumi - lebdi i njiha se u jednu bocu zatvorena, pa kad je deca upitaše: ' $\Sigma i ́ \beta v \lambda \lambda \alpha$, tí $\theta \varepsilon \dot{\lambda} \varepsilon ા \zeta^{\prime}$ (Sibila, šta želišs?), ona odgovori: à̆ก0 $\theta$ aveĩv $\theta \dot{\varepsilon} \lambda \omega^{\prime}$ (želim da umrem)" (Petronije 2007: 49). Premda i Olga Peters Hejsti (Olga Peters Hasty) i Hana Rutu (Hanna Ruutu) ubedljivo pokazuju da je neposredna inspiracija za Sibilu Cvetajeve bila Rilkeova istoimena pesma, važno je istaći da Sibila kao prazna posuda, kao glas bez tela nije 
njegova originalna ideja i, kao što smo pokazali, značajna je i za savremenika poput T.S. Eliota, a naposletku i za Silviju Plat kod koje nema dokaza o uticaju Rilkeove pesme. I u naslovu jedinog romana Silvije Plat, Staklenog zvona (The Bell Jar), primetna je analogija sa Petronijevom „dopunom" mita o Sibili: „Sibila je zatvorena u vrstu staklenog zvona, recimo, i žudi da, poput Silvije Plat, pobegne od egzistencije koja je guši, smrti-u-životu" (Haffenden 2003: 383). Takođe, u ranoj pesmi iz Kolosa (The Colossus) pod nazivom Dva prizora iz mrtvačnice (Two views of the cadaver room) lirski subjekt posmatra fetuse u staklenim teglama kao način da se mrtvo telo očuva u pseudoživotu, te je očito da motiv tela u tegli/posudi/sanduku ima razvojnu liniju u njenoj poeziji.

„Protejske osobine" (Broe 1980), odnosno maske koje lirski subjekt Silvije Plat preuzima u potrazi za sopstvom u vezi su sa ritualnim ponavljanjem simboličke smrti u pesmama poput Lala (Tulips), Liftinga lica (Face Lift), Rođendanskog dara (A Birthday Present) i mnogih drugih, od kojih je najpoznatija Ženski Lazar (Lady Lazarus), ali i ciklus o pčelama pripada nizu pesama u kojima je reintegrisanje (novog) identiteta lirske junakinje direktna posledica inscenirane smrti. Džon Rozenblat (Jon Rosenblatt) ističe trodelnu strukturu mitološke inicijacije: „stupanje u tamu, ritualnu smrt i ponovno rađanje" (Rosenblatt 1979: 23) tragom Elijadeovih (Eliade) antropoloških studija, a kod Silvije Plat se prva faza manifestuje kao transformisanje pejzaža u prostor smrti ili bar opasnosti, druga kao simbolička promena da bi se izbeglo nasilje, tj. smrt i naposletku "sopstvo iskrsava kao ponovo rođeno u novom svetu" (Rosenblatt 1979: 7). U Sastanku pčela uočljive su prve dve faze: nepoznat prostor ispunjen tuđim pogledima („NNezaštićena sam u letnjoj haljini bez rukava, / A oni su svi u rukavicama i pokriveni, zašto mi niko nije rekao" [Plat 2010: 139]) i simbolički preobražaj u nepomičnu, neuglednu biljku („NNe mogu da pobegnem, pustila sam koren, a žutilovka me ozleđuje (...)" i „Ako stojim sasvim mirno, pomisliće da sam divlja trava” [Plat 2010: 140]), da bi se pesma završila zagonetnim pitanjem: „Čiji je to beli dugački sanduk u gaju, šta su to oni uradili, zašto sam ja hladna?" (Plat 2010: 141) sugerišući da se lirska junakinja pretvorila u leš kao najviši stepen pasivnosti i ukidanja tela. U prvoj pesmi u ciklusu Marine Cvetajeve, Sibila prolazi kroz identične dve faze: u prvoj se njeno telo postepeno ukida („Sibila: spaljena, sibila: stablo"; „Sibila: naiskap, sibila: suša”, "Sibila: bila si, sibila: tama / sudbe i smrti! - Drvo među devojkama” [Cvetajeva 1990: 265]) da bi u potpunosti nestala („Iščeznu iz živih: sibila" [Cvetajeva 1990: 265]). U obema pesmama lirski subjekt postaje biljka, a kod Silvije Plat je aluzija na mit o Dafne dodatno naglašena stihovima "Ne bih mogla da pobegnem a da ne bežim zauvek. / Bela košnica je zaštićena kao devica" (Plat 2010: 140), u kojima se nasrtljiva grupa pčelara-isterivača matice poistovećuje sa progoniteljem Apolonom. Da nije reč 0 neodređenom poistovećivanju ginomorfnog i dendromorfnog pokazuje geneza ovog motiva kod Silvije Plat. U njenoj ranoj poeziji neretko se direktno imenuju mitološke figure koje će u zrelom periodu biti transformisane u suptilnije aluzije. Dafne se prvi put pominje u pesmi 0 teškoćama prizivanja drijade: „Moja je muka, doktore: Vidim drvo, / I to prokleto skrupulozno drvo ne izvodi trikove / Da bi zavaralo pogled: / Npr. nagibom svetlosti / Da stvori Dafne; /Moje drvo ostaje drvo" (Plath 1981: 66, naš prevod). „Lirska junakinja se žali na tvrdoglavo prisustvo, ili referencijalnost, sveta koji odbija da se transformiše u pesnički oblik" (Rose 2013: 114), odnosno obrće prvobitni mit i od drveta pokušava da stvori živu, pokretnu Dafne. Ipak, stvaranje prema modelu 
prirodnih formi uvek nosi mogućnost da pesma postane puka kopija, drugorazredni proizvod koji oponaša prirodni original i tada se pretvara u "nostalgiju za prirodnim objektom koji nikad ne može biti realizovan u jeziku" (Britzolakis 2001: 86). Dafne se pominje i u pesmi Devica u drvetu, nastaloj prema istoimenoj slici Paula Klea: „Još otkad je ta prva Dafne / Okrenula svoja neuporediva leđa / Radi skrivanja u lovoru, poštovanje je / Obmotano oko njenih ukočenih udova poput vrbe" (Plath 1981: 81, naš prevod). Dafne je prva osudila žene na muško „gomilanjem protivnagonskog" (Siksu 2006: 71), odnosno na puritansko proslavljanje ženske čistote kao jedinog ispravnog ispoljavanja ženske telesnosti. Stoga, pesnikinja žali devicu zarobljenu u drvetu jer je lišena čulnosti i mogućnosti da „iznese u tekst - kao i na svet, i u istoriju - svoj sopstveni pokret" (Siksu 2006: 67). U pesmi Vertikalna sam (I Am Vertical) lirska junakinja sebe definiše rečima: „Nisam ja drvo s korenom u zemlji" (Plat 2010: 79), te je očito da je u Sastanku pčela njen mitološki preobražaj u funkciji istraživanja novih aspekata identiteta.

Žena-biljka/drvo u kontekstu Sibile Marine Cvetajeve analizirana je van mitološkog konteksta (Ruutu 2006: 33), kao isticanje superiornosti Sibile spram ostatka zajednice ("Veličajno drvo u nagoj šumi" [Cvetajeva 1990: 265]), te se čini da je neobična slika „drveta među devojkama” u pesmi u svemu ostalom vernoj mitu o Sibili ostala neprotumačena jer se ne uklapa u nastojanja Olge Peters Hejsti i Hane Rutu da je interpretiraju kao prefiguraciju biblijskog narativa o Bogorodici. Već u prvom stihu, u kojem je "Sibila: spaljena, sibila: stablo" (Cvetajeva 1990: 265), nalaze se dva ključna elementa iz mita o Dafne: neobuzdani božanski plamen (Apolon) i žena-drvo (Dafne). U Sastanku pčela, Apolonov plamen je prefigurisan u sliku ljudi okupljenih da vatrom isteraju staru maticu iz košnice: „Kolutovi i pramenje dima u gaju. / Mozak košnice misli da je svemu kraj" (Plat 2010: 140), ali se bitno razlikuje perspektiva lirskog subjekta: u prvoj pesmi Sibile, tek se u šestoj strofi, i samo u njoj, pojavljuje lirsko ja poistovećeno sa Sibilom („Pa srcem i glasom - u mene - pade!” [Cvetajeva 1990: 265]), dok se u pesmi Silvije Plat sve vreme govori iz prvog lica. Kod Cvetajeve je Sibila pre „ulaska samog boga" u potpunosti deindividualizirana, odvojena od novog identiteta, te se ja isključivo može pojaviti u trenutku javljanja božanskog u telu-špilji, tradicionalno povezivanim sa mestom na kojem je Sibila prorokovala. Stoga, prva faza Sibile u kojoj se njeno telo preobražava u stablo i ritualno spaljuje, što Hana Rutu tumači kao „vatru pročišćenja" (Ruutu 2006: 33) kojom se Sibila inicira u novo, bestelesno sopstvo, može biti čitana i u erotskom ključu svojstvenom mitu o Dafne, a nedvomisleno prisutnom u evociranju ulaska boga u Sibilino telo i ognja koji pali telo-stablo. Ipak, Cvetajeva, uprkos trećoj pesmi ciklusa u kojoj se Sibila obraća detetu (simbolički, stvaranju posredstvom božanskog, što je i podstaklo čitanja u ključu Bogorodičinog bezgrešnog začeća), ne menja njenu devičansku prirodu koja je osuđuje na hiljadugodišnji život u telu koje stari i smanjuje se. Dafne se takođe preobražava u drvo upravo da bi sačuvala devičanstvo, što je u kontekstu dinamike košnice u pesmama Silvije Plat posebno kompleksno. Ogoljenost je u njenoj poeziji po pravilu povezana sa strahom od nasilja (Lant 1993: 19) koji inicira pseudomitske preobražaje, a u Sastanku pčela lirski subjekt se poistovećuje sa starom maticom koju meštani pokušavaju da isteraju vatrom iz košnice dok se ona, poput Sibile, „ne pokazuje" $i$ „stara je, stara, stara, mora da živi još godinu dana, i ona to zna" (Plat 2010: 140). Stoga, i kod nje i kod (vetajeve su u prvim dvema fazama ipak naglašeniji elementi mita o Dafne (telo-drvo, devičanstvo, destruktivni erotički 
oganj), da bi tek u trećoj fazi (rađanje novog identiteta) mit o Sibili bio prefigurisan u autoreferencijalnu sliku pesnikinje-proročice.

U prvoj pesmi ciklusa Cvetajeve, Sibila „iščezava iz živih" nakon ulaska boga u telo, a devet puta ponovljena reč "sibila" u drugoj pesmi se pretvara u obraćanje pesnikinje apstraktnoj i bezimenoj Drugoj. Bez naslova ciklusa i prve pesme, gotovo nemoguće bi bilo zaključiti da je reč o Sibili, posebno s obzirom na doslovno iščezavanje njenog biološkog tela iz tekstualnog, čime Cvetajeva dodatno naglašava božansku prirodu prefigurisane proročice. „Slepoća puškarnica” i „gluvoneme razvaline” (Cvetajeva 1990: 266) potcrtavaju odvojenost Sibile od ovog sveta, ali Kišov pogrešan prevod stiha iz prve pesme „под веками” („pod kapcima”) kao „pod vekovima” umnogome otežava razumevanje suštinskog pounutrašnjenja božanskog koje se Sibili javlja kao duhovni vid u onostrano i apstraktno. Svedena na špilju kao prostor u kojem odjekuje glas (Forrester 1992: 236), Sibila postaje vanvremeni svedok „glinenih krhotina / Carstava i drumske prašine // Bitaka..." (Cvetajeva 1990: 266) i njene proročke reči kojima je neophodno tumačenje čine je bliskom pesničkom stvaranju. Ipak, za Cvetajevu je ključan odnos tela i glasa, tj. nemogućnost žene-stvaraoca da upiše svoju telesnost u stvoreno, te otuda i Sibilina strepnja u trećoj pesmi za dete koje, jednom kad se otelotvori kao stvoreno, stupa u svet patnje i užasa. Ona je prazan sud za javljanje pesničkog glasa („Telo je tvoje špilja glasa / Tvojega" [Cvetajeva 1990: 266]), što u poeziji Cvetajeve, kako Sibelan Forester (Sibelan Forrester) pokazuje, ima dugu genezu kroz motiv ženskog tela-crkve kao segmentiranog prostora koji odjekuje i u kojem duhovno ima prevagu nad telesnim. Čini se da i ovaj ciklus pripada nizu pesama koje problematizuju strah od (erotskog) nasilja nad biološkim, ali i tekstualnim telom, primoravajući lirsku junakinju/pesnikinju da se preobrazi u apstraktni i nadasve društveno izolovani glas. Stoga, ako i možemo diskutovati maternalni princip u trećoj pesmi ciklusa u kojoj Sibila govori iz prvog lica, on odvaja žensko pesničko stvaranje od biološkog jer Sibili upravo devičanska priroda, odnosno ne-telo, omogućava da postane medijum božanskog. Čini se da Cvetajeva originalnu mitsku priču tumači kao alegoriju ženskog stvaranja, a erotske elemente iz oba analizirana mita pretvara u stvaralački plamen koji nije nužno u vezi sa Apolonovim jer on nigde nije eksplicitno pomenut, već sa ženom kao poeta vates-om kojase sjedinjuje sa božanskim. U tom smislu je razumljivo poređenje Sibile sa Bogorodičinim bezgrešnim začećem, ali je, čini se, ovde reč i o suštinskom zaokretu u mitološki utemeljenom poimanju žene kao muze, medijatorke između umetnika-muškarca i poezije. Sibila, pak, gubi svoje telo kao ekvivalent seksualnoj i biološkoj ulozi žene („Sibila: naiskap, sibila: suša. / Sve žile usahle: ljubomora muža!" [(vetajeva 1990: 265]), i kroz oticanje tela i telesnog, omogućen joj je (šuplji) prostor kroz koji glas odjekuje. Ovakva koncepcija ženskog stvaranja Cvetajeve svakako je suprotstavljena teorijama poststrukturalističkog feminizma koje nastoje da pronađu način na koji žena može svoje telo da upiše u jezički prostor, ali nam se čini da Cvetajeva ne negira telo po sebi, već njegovu svedenost na isključivo biološku funkciju - a odabir devičanstva uprkos posledicama, odnosno odabir drugog stvaralačkog puta za ženu, zajednički je mitovima o Dafne i Sibili.

Kad je reč o Silviji Plat, nije jednostavno razlučiti sloj mitološkog od narativa koji prati biografski potvrđene podatke da je pesnikinja u vreme pisanja ovih pesama počela da se bavi pčelarstvom, ali upravo na ovom primeru je očito da su još i rani kritičari opravdano isticali da su mitološki elementi i naglašena intertekstualnost ono što njenu 
poetiku odvaja od struje tzv. ispovedne poezije. Lirska junakinja je u Sastanku pčela suprotstavljena zajednici jednako kao što je Sibila izdvojena u špilji koja u ovoj pesmi postaje sanduk: „Čiji je to beli dugački sanduk u gaju, šta su to oni uradili, zašto sam ja hladna?" (Plat 2010: 141). Kod Silvije je, pak, za razliku od Cvetajeve, intertekstualna podloga kompleksnija s obzirom na to da postoji i suptilna aluzija na bezimenu biblijsku junakinju, Lotovuženu, u kojoj se prepliću elementi mita o Dafnei Euridiki: „Iscrpljena sam, iscrpljena - / Beli stub u pomračenju noževa. / Ja sam mađioničareva mala koja nikad ne ustukne" (Plat 2010: 141). Sanduk se, u ovom kontekstu, može tumačiti i kao standardni mađioničarski trik u kojem žena ulazi u malu drvenu kutiju i naočigled svih nestaje iz nje, a noževi figuriraju kao falički simbol kojem se lirska junakinja suprotstavlja pasivnošću, i trostrukom metamorfozom: u biljku (Dafne), u stub (Lotova žena) i naposletku u hladno telo u sanduku, ali glas ostaje (Sibila). U Prispeću košnice centralni motiv je ispitivanje prirode sanduka u kojima pčele (i junakinja) obitavaju, a samoispitivanje koje takav poduhvat iziskuje "sanduk manijaka" čini metaforom podvesti kojoj je "sanduk samo privremena stvar" (Plat 2010: 143). U stihovima "Pitam se da li bih bila zaboravljena / Samo da im brave otključam i sklonim se u drvo pretvorena" (Plat 2010: 143) najčvršće se povezuje ciklus o pčelama sa Dafne iz rane poezije Silvije Plat, a posledično i sa Sibilom, te se postavlja pitanje o granicama do kojih pesnikinja može da kontroliše svoj stvaralački nagon i opasnostima poniranja u sferu „pod kapcima". Sibilina špilja, a naposletku i ampulla, uvek su na ivici da postanu Pandorina kutija jer, kako obe pesnikinje pokazuju, forma (telo-sanduk-kutija-sud) nije sposobna da kontroliše sadržaj. (vetajeva lamentuje nad Sibilinim nerođenim detetom i njegovom sudbinom jednom kad napusti stvoriteljku (pesnikinju), dok Silvija Plat u poslednjoj pesmi ciklusa, Zimovanju, oslobađa pčele posle duge (stvaralačke) zime („Zima je za žene - / Žena, još uvek plete, / Kraj kolevke od španskog oraha, / Telo joj je lukovica na mrazu i odveć tupo da bi mislila" [Plat 2010: 153]) zabrinuta za sudbinu košnice („Da li će košnica preživeti” [Plat 2010: 153]).

Uprkos razlikama u obradi mitološkog izvora, obe pesnikinje kroz figure Sibile i Dafne opisuju inicijaciju žene-stvaraoca u poeziju i ispituju mogućnosti i, iznad svega, opasnosti kreativnog procesa. Smrt je u stvaralaštvu obeju pesnikinja neophodno razumeti kao jedan od ritualnih oblika kojim žena ispituje prostor svoje subjektivnosti u poeziji koja je vekovima bila muški poziv, te su i Dafne i Sibila u funkciji potrage za mestom ženskog tela i glasa u kulturnoj tradiciji. Marina Cvetajeva i Silvija Plat posežu za opštim mestima mitologije i poezije i prepisuju ih iz perspektive ženskih figura otvarajući uvrežene književne mitove mogućnostima ženskog stvaralačkog tumačenja, te se dve suštinski različite poetike ukrštaju u potrebi za pronalaženjem kulturnog prostora koji nije samo „špilja divnom glasu".

\section{LITERATURA}

Britzolakis, C. 2001. Sylvia Plath and the Theatre of Mourning. 0xford: Clarendon Press.

Broe, M. L. 1980. „Recovering the Complex Self: Sylvia Plath's Beeline”. The Centennial Review, Vol. 24, No. 1, 1-24.

Cvetajeva, M. 1990. Pesme i poeme. Priredila Milica Nikolić. Beograd: Narodna knjiga; Srpska književna zadruga. 
Forrester, S. 1992. „The Formative Role of the Female Body in Marina Tsvetaeva's Poetry”. Slavic Review. Vol. 51, No. 2, 232-246.

Görey, 0̈. 2000. Three Sibyls on a Tripod: Revisionary Mythmaking in the Poetry of H. D., Sylvia Plath, and Adrienne Rich. University of Leicester. Neobjavljena doktorska teza.

Gove, A. F. 1997. "The Feminine Stereotype and Beyond: Role Conflict and Resolution in the Poetics of Marina Tsveateva". Slavic Review, vol. 36, No. 2, 231-255.

Haffenden, J. 2003. "T. S. Eliot: The Waste Land". N. Roberts (ed.). A Companion to Twentieth-Century Poetry. Cornwall: Blackwell Publishing Ltd, 381-391.

Hasty, 0.P.2011. „The Body and the Voice: Marina Tsvetaeva's 'The Sibyl' and 'The Phaedra'”. S. Bahun-Radunović, V. G.J. Rajan (ed.). Myth and Violence in the Contemporary Female Text: New Cassandras. Farnham: Ashgate Publishing Limited, 115-130.

Lant, K. M. 1993. „The Big Strip Tease: Female Bodies and Male Power in the Poetry of Sylvia Plath". Contemporary Literature, Vol. 34, No. 4, 620-669.

Ovidije Nazon, P. 1991. Metamorfoze, prev. Tomo Maretić. Beograd: Grafički atelje Dereta. Petronije, A. 2007. Satirikon, prev. Radmila Šalabalić. Beograd: Artist.

Plat, S. 2010. Rani odlazak, prev. Ljiljana Đurđić. Beograd: Paideia.

Plath, Sylvia. 1981. The Collected Poems, ed. Ted Hughes. New York: Harper \& Row Publishers. Rose, J. 2013. The Haunting of Sylvia Plath. London: Virago.

Rosenblatt, Jon. 1979. „Sylvia Plath: The Drama of Initiation”. Twentieth Century Literature, Vol. 25, No. 1, 21-36.

Ruutu, H. 2007. Patterns of Transcendence - Classical Myth in Marina Tsvetaeva's Poetry of the 1920s. University of Helsinki. Neobjavljena doktorska teza.

Siksu, E. 2006. „Smeh meduze”. Pro Femina: časopis za žensku književnosti i kulturu, god. 10, br. 43/45: 67-81.

\section{SUMMARY}

\section{MYTHS OF SIBYL AND DAPHNE IN THE POETRY OF MARINA CVETAEVA AND SYLVIA PLATH}

This paper examines a three-poem cycle Sibyl by Marina Tsvetaeva and a so-called bee-cycle consisting of five poems from Ariel by Sylvia Plath in the context of myths of Sibyl and Daphne. A special attention is paid to the first two poems from both cycles in order to determine similarities between poetics of American and Russian poetesses. The figures of Daphne and Sibyl are both presented in a specific way in one lyrical heroine whose process of initiation in poetic creation is described through resemantization of mythic narrative.

KEYWORDS: myth, Daphne, Sibyl, Sylvia Plath, Marina Tsvetaeva, initiation, poetry.

(Originalni naučni rad primljen 29.5.2017; ispravljen 24.11.2017; prihvaćen 1.12.2017) 